\title{
Urban Kindness: Parametrization and digital fabrication powering forgotten spaces
}

\section{SIGRADI2018 TECHNOPOLITICAS \\ xxii congresso da sociedade iberoamericana de gráfica digital 22th conference of the iberoamerican society of digital graphics 07|08|09|novembro|2018 iau usp | são carlos | sp br}

\author{
Mayara Dias de Souza \\ UFMS | Brazil | mayara.dias@ufms.br \\ Gilfranco Medeiros Alves \\ UFMS | Brazil | gilfranco.alves@ufms.br \\ Natália de Andrade Corrêa \\ UFMS | Brazil | natalia.correa@ufms.abea.arq.br
}

\begin{abstract}
The goal of this paper is to present and discuss the design process of a intervention realized in a historic building placed in Campo Grande/MS, Brazil. The project had as premise the invitation to use, coexistence or contemplation in the previously degraded and unused space. The project was carried out through the partnership between the algo+ritmo research group from UFMS and the Casa de Ensaio, a non-profit organization. The main goal was that students of architecture and urbanism could use digital technologies to design, developt and executate the project, and also control the whole process from the beginning to the end.. Through the evaluation of the results, this paper reflects on procedures used in undergraduate courses seeking to contribute to the dissemination of other forms of design processes different from conventional ones.
\end{abstract}

Keywords: Urban intervention; Urban kindness; Project process; Parametric Design, Digital Fabrication.

\section{INTRODUÇÃO}

Intervenções urbanas constituem uma arte propositiva e questionadora das relações das pessoas (público) com o espaço/lugar. O reconhecimento das diversas temporalidades no espaço público, a noção de efêmero e a identificação dos espaços em fluxo, cerceiam o tema em defesa da inserção contínua e variada de estímulos físicos na cidade como convite à interação pública: a compreensão de lógicas relacionais centradas em experiências e vivências pessoais e coletivas dos usuários; o reconhecimento do espaço da oportunidade nos quais os projetos sugerem determinadas performances, mas se mantêm simultaneamente abertos, flexíveis e adaptáveis à apropriação espontânea. Neste sentido, este artigo discute o processo de projeto de uma intervenção em edifício histórico na cidade de Campo Grande, no estado de Mato Grosso do Sul.

Tal projeto teve como premissa o convite a utilização, convivência ou contemplação no espaço antes degradado e inutilizado. O termo "gentileza urbana" foi utilizado como conceito de projeto, a medida em que contempla iniciativas de obras que agregam intervenções para favorecer o urbanismo e o paisagismo público em seu entorno. O principal objetivo foi que alunos de graduação em arquitetura e urbanismo utilizassem tecnologias digitais disponíveis para elaboração, desenvolvimento e execução do projeto e acompanhassem todo o processo. O computador não foi utilizado apenas uma ferramenta de representação de projeto, mas fez parte de um processo de concepção e produção. Pesquisadores conceberam relações, estruturas e procedimentos para o desenvolvimento do projeto, além de estudarem sobre linguagens de programação para se capacitarem ao desenvolvimento de geometrias complexas e processos produtivos realizados de forma paramétrica. A incorporação da produção dos modelos físicos como parte do processo para a verificação das soluções construtivas adotadas foi essencial no andamento do processo porque permitiu antecipar ajustes no projeto e minimizar erros. As técnicas de fabricação digital, por sua vez, utilizadas em modelos e protótipos antecipou a produção em escala 1:1. O design paramétrico e a fabricação digital tiveram como base referencial teórica, os trabalhos de diferentes autores, como Iwamoto (2009), Kolarevic (2009), Woodbury (2010), Oxman (2006) e Alves (2014).

O projeto foi realizado através da parceria entre a universidade Federal do Mato Grosso do Sul (UFMS) e a Casa de Ensaio, uma organização sem fins lucrativos. O processo colaborativo englobou desde a necessidade de identificar um espaço potencial para intervenção, as estratégias de aproximação com os agentes envolvidos, de modo a despertar o engajamento coletivo dos usuários da casa. Um engajamento que vislumbra não somente em melhorias na qualidade de projeto, na manutenção de infraestrutura urbana, mas também no estabelecimento de uma relação com o espaço, que também interfere na consolidação de significados e identidades locais. 


\section{METODOLOGIA}

Os procedimentos metodológicos utilizados basearam-se nas seguintes etapas: revisão bibliográfica, reuniões técnicas com pesquisadores, funcionários e dirigentes da Casa de Ensaio; desenvolvimento de projeto utilizando o software Rhinoceros, em conjunto com seu plugin Grasshopper; prototipagem da estrutura geral para estudo de volumetria e definição de materiais e encaixes; fabricação digital em escala 1:1, montagem e instalação no local.

A temática do projeto foi idealizada pela professora Maria Lúcia Torrecilha, da UFMS, que também fazia parte da equipe da Casa de Ensaio. Com a parceria estabelecida com o Algo+ritmo, grupo de pesquisa da mesma universidade, que estuda e pesquisa processos digitais de projeto e fabricação, buscou-se o desenvolvimento do projeto baseado em conceitos abordados por referenciais teóricos como Jan Gehl e Jeff Speck. Ambos autores defendem o convite a utilização da cidade através de caminhadas. Para Gehl, por exemplo, o convite deve incluir a opção de se sentar e passar um tempo na cidade Atividades de permanência, para esse autor, são a chave de uma cidade viva, mas também realmente agradável. As pessoas ficam se um lugar for bonito, significativo e agradável. Uma boa cidade tem muitas semelhanças com uma boa festa: os convidados ficam porque se divertem (Gehl, 2010, p.147).

\section{INSERÇÃO DO PROJETO}

O projeto está inserido em um edifício histórico na cidade de Campo Grande, no estado de Mato Grosso do Sul. Tal edifício passou por várias reformas e diferentes usos. Seu uso mais recente, antes de abrigar seu uso atual, era como albergue municipal, até que a prefeitura comprou o edifício e iniciou a retomada de posse, e este passou a sediar a organização social formada por uma equipe de artistas profissionais que transformaram o espaço em um centro cultural. De acordo com o Instituto Municipal de Planejamento Urbano, "o prédio não é patrimônio tombado em nenhuma esfera governamental, mas a estrutura externa do prédio foi preservada porque faz parte da memória da população".

O espaço de implantação do projeto localiza-se na fachada secundária do edifício sede da organização. Tratava-se de uma reentrância no recuo de ajardinamento, com pouca iluminação e visibilidade, gerando grande degradação causada por antigos usuários do albergue, usuários de drogas, moradores de rua e conflitos entre gangues no local central da cidade. Conflitos que por sua vez causaram anteriormente danos às janelas existentes na fachada, são as janelas da biblioteca usada pelas crianças para leitura e outras atividades. Caso esse espaço não fosse revitalizado por algum meio, seriam colocadas grades semelhantes a da fachada principal, bloqueando o contato com a área externa e criando mais uma fachada cega e sem interação alguma com as pessoas



Figura 1: Fachada atual da Casa de Ensaio onde o projeto foi implantado. Fonte: autores.

\section{DESCRIÇÃO DO PROJETO}

O projeto é composto por 10 módulos de meia esfera, com 12 hastes cada, com pelo menos uma delas conectada com outra esfera, de forma que todas as 10 esferas estão conectadas entre si. Os módulos de meia esfera estão divididos em 4 tamanhos. Também varia a quantidade de discos horizontais necessário para estruturar cada módulo. Cada uma das medidas da estrutura foi parametrizada de forma que variações foram geradas a partir do script proposto criando uma composição de módulos com alturas, diâmetros e números de peças horizontais diversos.

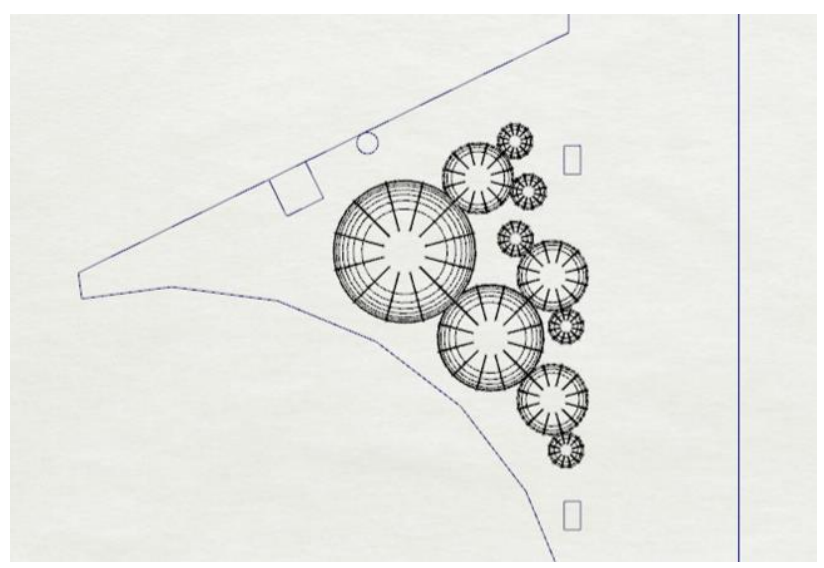

Figura 2: Implantação do projeto da gentileza urbana no espaço degradado. Fonte: autores.

Como Processo de Projeto Paramétrico entendemos como sendo um método fundamentado em técnicas de criação e modelagem digital, a partir de sistemas de programação que antecipam a tomada de decisões para uma etapa bastante inicial do processo de projeto - a fase de definição dos parâmetros (inputs). Um parâmetro pode ser entendido como o valor de uma variável que, ao mudar, fornece uma característica diferente ao componente, mas mantém uma relação tipológica inicial com este componente em seu estado original (Alves, 2013). 


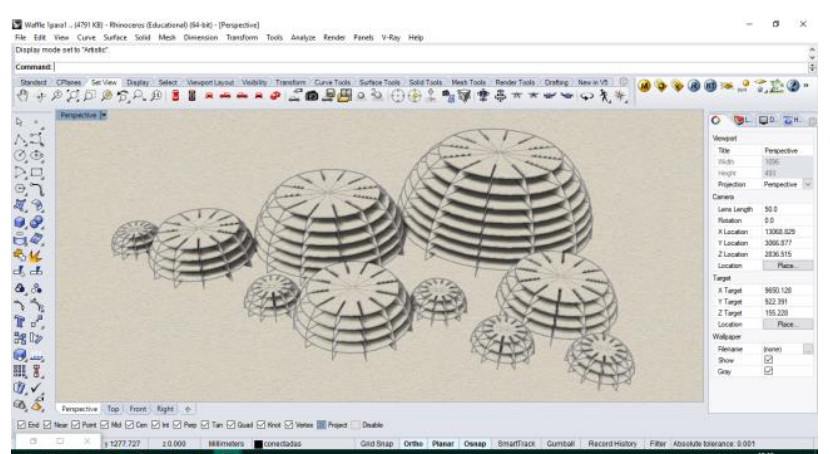

Figura 3: Volumetria isolada do projeto da gentileza urbana. Fonte: autores.

O software Artcam também foi utilizado, nele foram configurados os percursos de corte das chapas na CNC fresadora.

Posteriormente à modelagem digital primária baseada nas conclusões das reuniões e estudos de espacialidades, usos e estrutura, foram iniciadas as prototipagens. Primeiramente, foram planificadas as peças de um modelo primário em escala reduzida não definida, para corte na CNC do próprio grupo de pesquisa. Após o corte das peças em papel paraná, lixamos para montagem. As peças mostraram-se frouxas nos encaixes e sua forma inicial era elíptica, o que acarretou num modelo alto e pouco estruturado. A estrutura foi avaliada e decidiu-se alterar os parâmetros até que uma proporção ideal para cumprir os objetivos fosse encontrada.

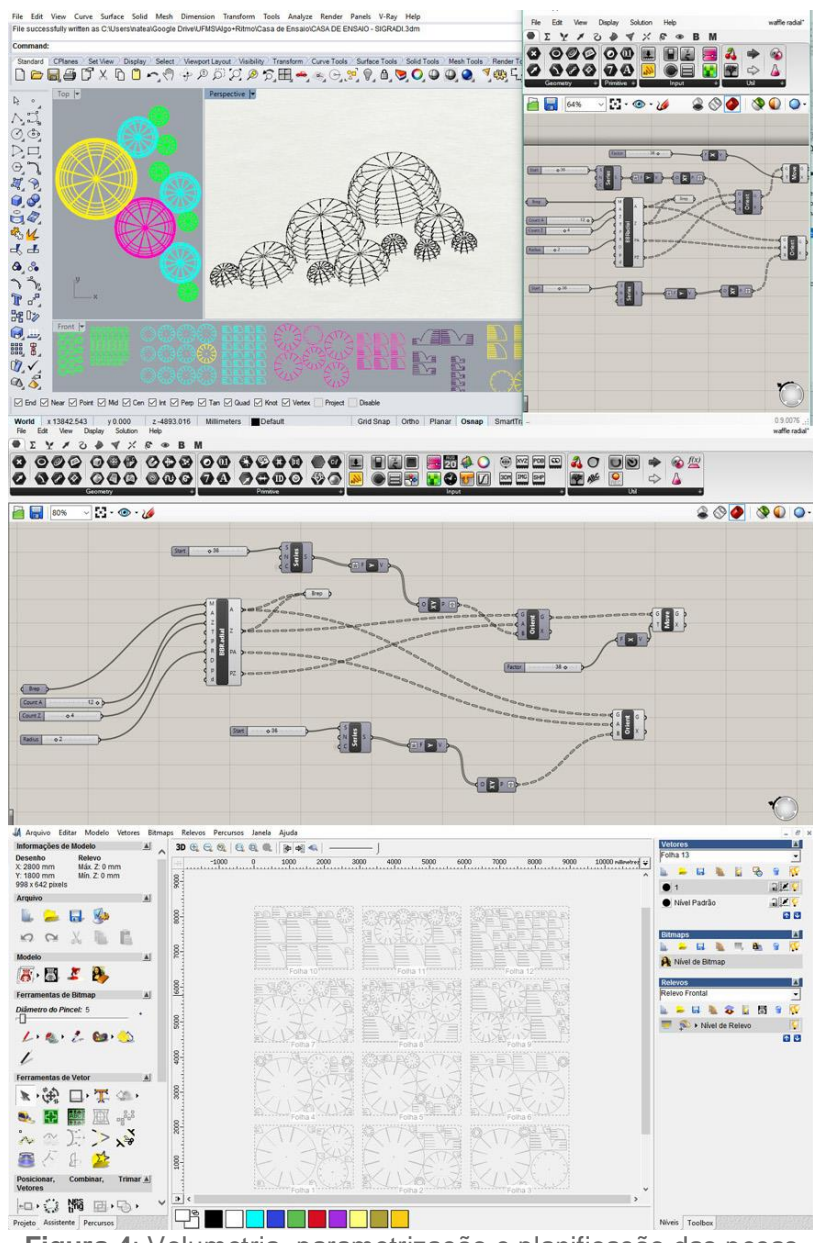

Figura 4: Volumetria, parametrização e planificação das peças no Rhinoceros, script no Grasshopper e Artcam. Fonte: autores.
Após os testes, com a proporção ideal definida, foram criados módulos. Cada módulo possuía parâmetros distintos, porém com a mesma proporção. Quanto mais alto, maior o diâmetro e mais divisões verticais, e viceversa. As divisões radiais mantiveram-se as mesmas para todos os módulos. Posteriormente à divisão em módulos, e a distribuição de forma fluida no espaço de intervenção, optamos pela criação de peças conectores ligando cada um dos módulos a pelo menos outro módulo.

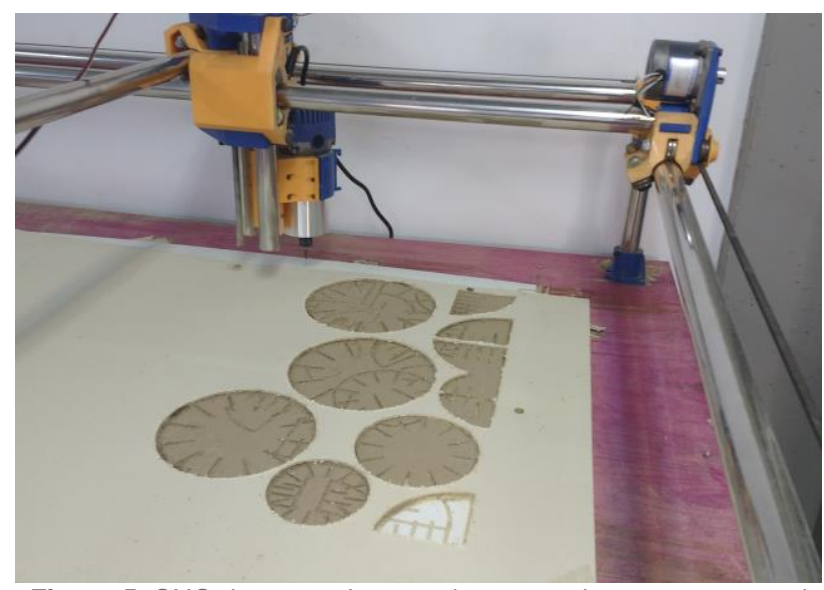

Figura 5: CNC do grupo de pesquisa cortando peças em papel paraná para prototipagem. Fonte: autores.

Após o corte, foi necessário lixar cada peça para remover farpas geradas pela fresadora durante o corte e melhorar o acabamento da peça, primeiro com uma lixa grossa e depois com uma lixa mais fina. Após lixar as peças, foram passadas três camadas de stein para impermeabilização e acabamento ideal.

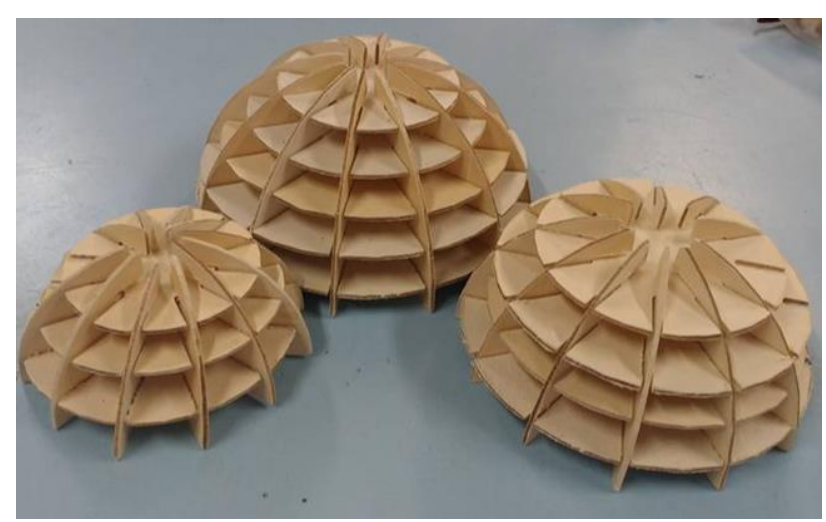

Figura 6: Protótipos já montados com as peças de papel paraná para estudos volumétrico e estrutural. Fonte: autores.

Após a impermeabilização, as cantoneiras em conjunto com os parafusos e porcas foram utilizados como pés para elevar a estrutura alguns centímetros do solo. Enquanto isso uma base de concreto foi instalada no espaço de implantação da gentileza urbana para evitar contato com a umidade do solo, e os pés afastam a umidade do próprio concreto.

Após o processo de preparação das peças e instalação dos pés com fixação das porcas com cola de contato, algumas partes foram melhor lixadas para facilitar o processo de encaixe, pois ao impermeabilizar com stein as peças sofreram um leve estufamento. 
Os primeiros módulos a serem encaixados foram os menores, até chegar aos maiores. Nos módulos maiores foram necessários apoios sob as abas dos discos para estabilidade da estrutura ao receber cargas pontuais. Esses apoios foram criados utilizando uma porca e um parafuso por aba, utilizando cola de contato para fixar as abas e as porcas.

Os módulos foram levados para a base de concreto e conectados utilizando as peças conectoras, fixando com cola de contato. Após seguir os planos de encaixe e com todos os módulos conectados por pelo menos uma peça vertical, os pés foram fixados na base utilizando cola de contato, assim como os tampos, criando a superfície da gentileza.

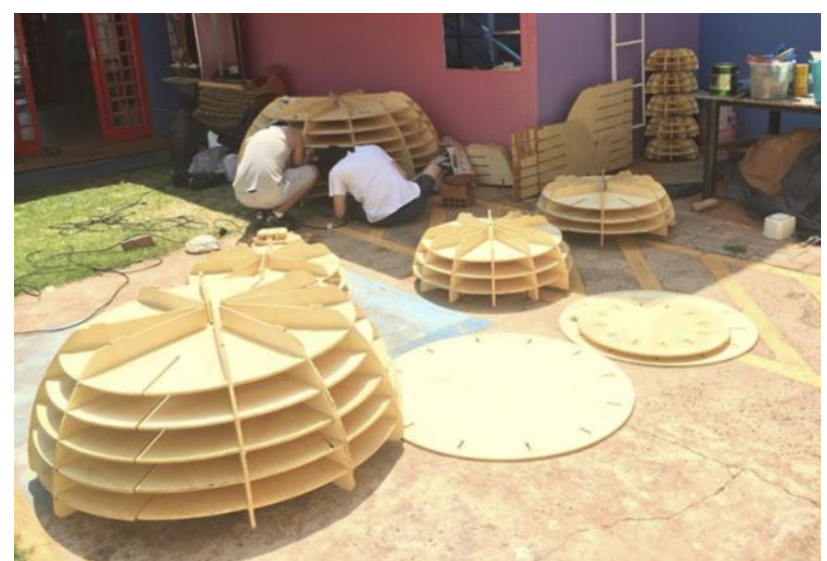

Figura 7: Processo de montagem dos módulos antes de instalar na plataforma de concreto. Fonte: autores.

As peças resultantes do projeto final foram planificadas e organizadas em pranchas bidimensionais no software Artcam, para serem exportadas com as configurações de corte necessárias para que a CNC fresadora do nosso parceiro do grupo de pesquisa executasse o corte de forma precisa em compensado naval.

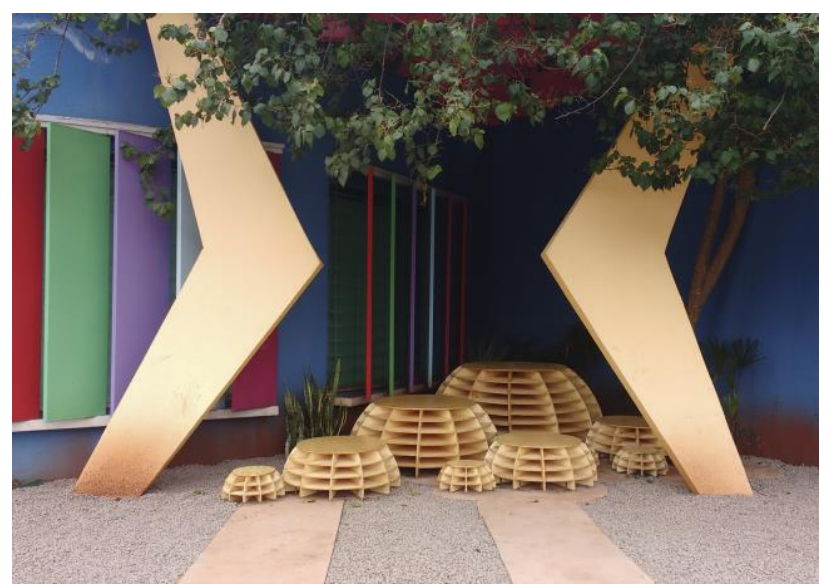

Figura 8: Projeto finalizado. Fonte: autores.

\section{RESULTADOS}

Um projeto desse teor, do começo ao fim, oferece uma vasta gama de experiências, tanto para estudantes e professores envolvidos, como para o espaço em que o projeto foi inserido, incomum algo desse gênero em espaço público nesta capital.
No processo, os envolvidos diretamente com a criação e com a execução puderam explorar do começo ao fim o que cada etapa exigiu: planejamento de todas as etapas, utilização de software, orçamento, cronograma que incluía cada etapa e previsão de atrasos e empecilhos. Ou seja, entender todo o processo de projetar e executar uma obra de verdade e não somente existente no plano da idealização.

Professores e alunos envolvidos no processo de criação, prototipagem e execução do projeto tiveram seus conhecimentos enriquecidos tanto em termos metodológicos, quanto de processo projetual nessa área ainda pouco explorada na região. Parcerias com profissionais externos à universidade também alimentaram a experiência. Os primeiros resultados físicos foram os protótipos. A prototipagem não foi meramente representativa, fez parte do processo de projeto com a criação de objetos de estudo cortados pela CNC em papel paraná.

No primeiro protótipo foram analisadas as proporções e o funcionamento dos encaixes. No segundo protótipo, focou no experimento de como alturas variadas dos módulos e suas peças conectoras funcionavam. O terceiro protótipo foi um aprimoramento dos encaixes e das proporções mais próximas as selecionadas para o modelo a ser executado. O quarto protótipo foi executado em escala 1:1, um teste do menor módulo do projeto final, onde foram testadas resina líquida, os encaixes, a cola de contato, a colocação das cantoneiras como pés, e a resistência do material com as peças encaixando de forma radial.

Alguns protótipos foram feitos na impressora 3D para estudo da melhor volumetria para os pés que elevariam os módulos. Porém, o material final escolhido para esse fim, foram as cantoneiras dispostas de forma dupla sob as peças verticais, presas e apoiadas por parafusos e porcas.

Certos detalhes construtivos que foram previstos no começo para o modelo final não puderam ser executadas da forma prevista, como por exemplo a resina que cobriria os tampos de cada um dos módulos. A princípio o teste feito no quarto protótipo 1:1 funcionou, mas ao ser aplicada nos tampos com impermeabilização feita pelo Stein, a resina rachou e não aderiu a madeira como no teste.

O projeto finalizado e suas formas incomuns visou instigar a identificação de signos diferentes por cada observador. Impressões e assimilações da obra expõe como a semiótica em relação ao design trabalha na cabeça de cada um. As percepções foram registradas e geraram uma lista com o que cada pessoa foi capaz de abstrair visualmente da gentileza urbana que, além de física também tornou-se uma gentileza visual para a imaginação dos transeuntes. 


\section{DISCUSSÕES}

As impressões que as pessoas têm sobre a cidade, ou um local em particular, são mais do que visuais. A cidade oferece uma quantidade imensa de sensações. As memórias, odores, esperanças, multidões, lugares, edifícios, o drama da vida e da morte, que a compõem, afetam cada pessoa, diferentemente. Em cidades estão cada vez mais hostis e excludentes, voltadas para o individualismo, a gentileza urbana pode ser pensada como resistência na medida em que chama a atenção para outros tipos de relações.

Cada vez mais as populações das cidades são maiores, mas estudos mostram que as pessoas se sentem mais isoladas do que nunca. Como as relações nos bairros têm declinado através das últimas décadas, uma das grandes missões das cidades modernas é voltar a criar uma comunhão emocional.

Num mundo em que as cidades estão cada vez mais hostis e excludentes, voltadas para o individualismo, com trânsitos violentos, árvores cortadas, a gentileza urbana pode ser pensada como resistência na medida em que chama a atenção para outros tipos de relações. Projeto de mobiliários podem ser a ponte para essas relações, como destaca Gehl, o mobiliário urbano pode trazer uma contribuição valiosa aos encontros no espaço das cidades, como por exemplo o agrupamento de bancos criando uma "paisagem para conversa" (Gehl, 2010, 155).

\section{AGRADECIMENTOS}

Agradecemos a Universidade Federal do Mato Grosso do Sul pelo apoio financeiro à participação nesse evento.

\section{REFERÊNCIAS}

ALVES, G. Cibersemiótica e Processos de Projeto: Metodologia em Revisão. São Carlos, 2014. Tese (doutorado), Instituto de Arquitetura e Urbanismo (IAU), Universidade de São Paulo (USP).

DUNN, Nick. Digital Fabrication in Architecture. London: Laurence King, 2012.

GEHL, Jan. Cidades para Pessoas. São Paulo: Perspectiva, 2010

KOLAREVIC, Branko. Architecture in the Digital Age: Design and Manufacturing. New York: Sppon, 2003.

MEREDITH, Michael. From Control to Design. New York: Actar-D, 2008.

OXMAN, Rivka e OXMAN, Robert. Theories of the Digital in Architecture. Abington: Routledge, 2014.

SPECK, J. A Cidade Caminhável. São Paulo: Perspectiva, 2016.

ROGERS, Richard. Cidades para um pequeno planeta. São Paulo: GG, 1997

VIVANT, Elsa. O que é uma cidade criativa? SENAC. 2017

WOODBURY, Robert. Elements of Parametric Design. New York: Routledge, 2010. 